\title{
Impact of Building Form on Energy Performance in New School Models
}

\author{
Meriem Rahmani, Khaled Al-Sallal \\ UAE University, Al Ain, UAE
}

\begin{abstract}
This study investigates methods to optimize energy performance of school buildings by proper design of the building form. It relied on building energy simulation to evaluate the new design models proposed by Abu Dhabi Department of Education and Knowledge (ADEK). The investigations went through three stages, in the first one the study examined the impact of different Learning Community (LC) and Courtyard (C) aspect ratios on energy consumption. In the second stage, it examined the impact of different building heights (i.e., number of floors), when combined with $\mathrm{LC}$ and $\mathrm{C}$ variables, on energy consumption. The third stage tested the same previous variables under two different form axis directions (East-West and North-South). The results of the first stage indicate that forms with a more linear proportion of the $\mathrm{LC}$ and $\mathrm{C}$ perform better than those with a squared proportion. Moreover, linearlyproportioned Cs achieved better energy savings than linearly-proportioned LCs. Results of the second stage revealed the significance impact of the building's vertical proportion (i.e., form verticality as represented by the number of floors) on energy reduction; the cases with two floors proved to perform better compared to those with one floor, both having the same floor area. Results of the third stage confirmed a consistent pattern with the results of the previously investigated variables at two different orientations; yet, the cases with the N-S form axis direction performed better than the cases with the $\mathrm{E}-\mathrm{W}$ form axis direction.
\end{abstract}

\section{Introduction}

Energy consumption rates in school buildings in the UAE have been increasing sharply since the seventies when UAE was formed and a modern educational system was needed. The increase in energy is attributable to the high reliance on electrical and mechanical systems instead of passive design strategies for the provision of lighting and cooling, which leads in parallel to an increase in GHG emissions. The impact of the complete dependance on electrical and mechanical systems is not limited to the exessive usage of energy and its consequences with regards to the GHG emissions, it also deprive occupants from daylighting and natural cooling which proved to impact their health. The impact of daylighting for example on occupants health and performance has been tackled most importantly in schools as it effect significanlty the students.

Liselie, R. in her book "Patterns to Daylight Schools for People and Sustainability" discussed in details the importance of having sufficient daylight that contain the short-wavelength (blue) light that is necessary to stimulate the biological clocks and thus enhance the student's performance (Leslie, 2010). Frumkin discussed the same idea. Where he ensured from his researches that the abundance of natural lighting besides the good indoor air quality and humidity control which are features of sustainable schools can impact the student's health significantly which will be reflected on the students by improving their performance and as well lowering the rates of their absenteeism (Frumkin, Geller, I., Rubin, \& Nodvin, 2006).

According to the Environmental and Protection Agency (EPA) one out of five school children in the US were dissatisfied with the indoors' air quality (EPA, 2009). Abu Dhabi Water and Electricity Company (ADWEC) stated that the building sector in Abu Dhabi city consumes $80 \%$ of the total consumed energy (Clarke, 2016). The high rates of energy consumption by the building sector in UAE is a result of the excessive use of cooling systems due to the harsh climatic conditions. The UAE's weather is classified as one of the harshest; it is very hot in summer as extreme temperatures can reach up to or exceed $50^{\circ} \mathrm{C}$ between July and August, while in winter it ranges from warm to moderate conditions (AlMandoos, 2005). Improvement of the building design is the key to minimize the massive heat gains in such extreme conditions.

The New School Model (NSM) which was introduced by Abu Dhabi Department of Education and knowledge (ADEK) to improve the entire educational system is one of the initiatives that Abu Dhabi launched as a part of its 2030 vision. This was for the purpose of enabling all schools in UAE to operate under one standarized framewrok. ADEK has produced a Design Manual that includes several design criteria and recommendations for designers to follow and based on it ADEK approved several new design models. The new design models are based on the finger plan concept, where each finger represents one Learning Community (LC) that usually contain; 4-5 classrooms, a central break out space, and 
laboratory (ADEK, 2013). These models rely on passive design strategies; such as; daylighting and shading devices, besides the instalment of efficient mechanical and electrical systems (Educational Facilities Design Manual, 2013). This study aims to integrate with ADEK efforts by testing the impact of the school building form on energy consumption.

\section{Literature Review}

Based on extensive number of parametric combinations between the building shape, orientation, window to wall ratio, construction types and materials, and the occupant behaviour evaluated in 8 different climatic conditions using building energy simulation, Naboni et al. (2015) found that there is a great potential for energy savings (between $63 \%$ to $76 \%$ depending on the climate) when proper architectural design decisions were made. A carful selection of the building elements including the proper form, orientation, shading devices, openings and building material can lead to maximizing the energy savings. Al Sallal (2016) illustrated several important considerations that can be implemented in the early stages of design to reduce heat gain in buildings; these are: giving priority to self-shaded forms to help reduce the exposure to the sun, the use of compacted forms in hot dry climates to help reduce the surface area being exposed to the harsh outdoor conditions (high solar radiation and high ambient temperature) and as a result prevent heat gain.

The impact of building orientation on energy performance is dependant on its shape (AlAnzi, Seo, and Krarti, 2009). Several studies tested the impact of building form on its energy performance (AlAnzi, Seo, and Krarti, 2009; Catalina, Virgone, and Iordache, 2011; Depecker et al., 2001; Koranteng and Abaitey, 2010; Ourghi, Al-Anzi, \& Krarti, 2007). A common parameter between these studies was the building compactness, which can be defined as the ratio of the building volume to its exterior surfaces. Al Anzi at al. (2009) stated that there are three factors that can influence the impact of building shape on energy performance; these are the relative compactness ( $\mathrm{RC}$ ) of the form, the window to wall ratio (WWR) and the solar heat gain coefficient (SHGC) of the glazing. It pointed out that when two buildings have the same RC they do not necessary have a similar energy performance as they might differ in their exposure to solar radiation. Mahdavi and Depcker conducted two different studies to investigate the impact of the building shape on its energy consumption, both in cold climates. Both studies concluded that building shape has a direct impact on energy consumption; the increase in the building's compactness leads to a decrease in energy consumption. Hence, recommending compact forms for their capacity to save energy can be understandable since they have less exposure through their limited exterior surfaces to the ambient conditions (Pessenlehner and Mahdavi, 2003; Depecker et al., 2001).
A previous study conducted in the hot climate of Kuwait investigated how different building shapes affect energy consumption under different WWRs ( 0 vs $50 \%$ in clear glazing). The results of both WWR cases showed that buildings with high RC consumed less cooling energy. This can be understadable since these buildings have less external surfaces exposed to the outdoor conditions. Hence, the RC was recommended as an indicator for energy efficiency (AlAnzi, Seo, and Krarti, 2009). Another study carried out in France using simulation tested different building morphologies under different WWR and climate scenarios. The results confirmed the conclusions reached by previous studies with regards to the benefit of compact forms in reducing energy consmption. However, it argued that a very compact shape like the cube is efficient in terms of thermal energy reduction but not for daylighting because the amount of daylighting entered into the building cannot reach to deeper spaces; and as a result more energy will be needed to operate artificial lighting systems. A 30\% difference in the illuminance levels was recorded between the cubical shape (244 lux) and rectangular shape (366 lux). In contrast, a reduction of 6-10\% in heating energy demands for more compact shapes. Moreover, the glazing size and its distribution also have a remarkable impact on energy consumption (Catalina et al., 2011). Lechner (1991) stated in his book that even though compact shapes are preferable as they proved to be more energy-efficient because they gain and loose less heat during day and night, but very compact shapes are not recommended as they require more artificial light due to the lack of daylighting. The artificial light will eventually release more heat and thus require more cooling energy. Compacted shapes require careful attention and calculations to not compromise the benefits of daylighting.

\section{Methods}

This study investigates how different design form configurations, generated by changing the horizontal and vertical aspect ratios of the $\mathrm{LC}$ and $\mathrm{C}$ under different orientations, affect energy consumption of the school building. It takes into considration the design standards and recommendations to adopt the finger floor-plan layouts, as proposed by ADEK. In this regard, the results of this study will be valid representative of realistic cases. In the beginning, several methods were used for data collection that included literature review, published materials about development and design specs of schools in Abu Dhabi, and water and electricity tariffs. This is followed by conducting an extensive survey of existing schools in Abu Dhabi Emirate using School Finder application provided by ADEK. The School Finder helped obtain the GPS coordinates of the desired schools that are entered into Google maps to find the school layouts of the surveyed cases from which their building shapes were obtained. The survey covered the new design models of the public schools as these are and will 
be more common in use and significant for the country's future plans. The old school designs are no longer authorized by ADEK due to several issues including poor performnace for sustainability. The new design models were analysed in order to determine the possible geometric form variables with their ranges. Four (4) existing schools under the category of the new design models were selected, each school represented a unique model. These models differ in terms of their student capacity, (see Figure 1). The following points summarize the variables found in the case studies with their value ranges:

- Learning community (LC) width-to-length aspect ratio: ranging from $1: 1.38-1: 1.5$

- Courtyard space width: $0-14 \mathrm{~m}$

- The number of floors: 2-3 (most of the cases are 2)

- Form orientation (common): (N/W-S/E) and (N/E$\mathrm{S} / \mathrm{W})$.

The outcomes from the case study analysis helped to develop the building models for simulation. A modular system, based on a module of $1.25 \mathrm{~m}$, was adopted. This helped to maintain the same floor area for all the cases and hence gurantee fair comparison and valid results.

This study examined four (4) variables (See Figure 2); first, the LC form proportion ranging from almost square to rectangle shape (width-to-length aspect ratio ranging from 1:0.8 to 1:1.8); second, the outdoor spacing between the LC finger masses (courtyard width ranging from 10 to $30 \mathrm{~m}$ ), third, the number of floors (1 or 2 floors); and finally, the form orientation (East-West or North-South form axis directions). Other variables that were not identified as part of the form design configuration (as stated above) were controlled with fixed values, obtained also from the case studies and the Educational Facilities Design Manual by ADEK (Table 1 lists the constant variables with their values).

Table 1: Constant variables among the cases with their values.

\begin{tabular}{|l|l|}
\hline Constant Variables & Value \\
\hline Floor Area & $3050 \mathrm{~m}^{2}$ \\
\hline WWR & $35 \%$ \\
\hline Glass U-Factor & $6.814 \mathrm{Watt} / \mathrm{m}^{2} . \mathrm{C}$ \\
\hline Wall U-Factor & $0.505 \mathrm{Watt} / \mathrm{m}^{2} . \mathrm{C}$ \\
\hline Roof U-Factor & $0.358 \mathrm{Watt} / \mathrm{m}^{2} . \mathrm{C}$ \\
\hline Occupancy densities & $\begin{array}{l}\text { Based on ASHRAE 90.1 } \\
2010 \mathrm{standards}\end{array}$ \\
\hline $\begin{array}{l}\text { Electrical lighting } \\
\text { power densities }\end{array}$ & $\begin{array}{l}10.7 \mathrm{~W} / \mathrm{m}{ }^{2} \text { Based on } \\
\text { ASHRAE } 90.12010\end{array}$ \\
\hline Ventilation rates: & $\begin{array}{l}\text { CS1.829 L/s/ m² Based on } \\
\text { ASHRAE 62.1 standards }\end{array}$ \\
\hline
\end{tabular}

\begin{tabular}{|l|l|}
\hline Ceiling height: & $3.75 \mathrm{~m}$ \\
\hline HVAC system & $\begin{array}{l}\text { VAV w/ parallel FCU } \\
\text { (Cent. Chilled Water C.T. })\end{array}$ \\
\hline $\begin{array}{l}\text { Electrical lighting } \\
\text { system }\end{array}$ & $\begin{array}{l}\text { Fluorescent tubular 100 } \\
\text { Lum/watt }\end{array}$ \\
\hline Exterior Exposure & Grass \\
\hline $\begin{array}{l}\text { Target lux in } \\
\text { classrooms }\end{array}$ & 500 Lux \\
\hline
\end{tabular}



Figure 1: Layout of forms of the case studies.

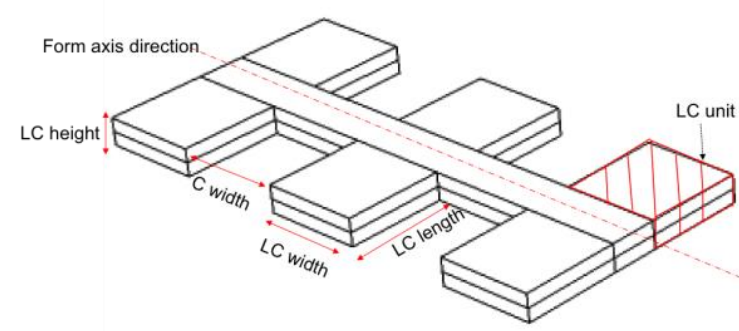

Figure 1: Representation of the form variables.

The prepared cases went through three different stages of testing.

Stage One - Effect of LC and C Proportion: aims to understand fully the dynamic behaviour of changing the horizontal form proportions (in two dimensions $\mathrm{X}$ and Y). A total number of 25 different cases were modeled to help investigate the issues related to building form in a regulated way (see Figure 3). The modeled cases included 5 different LC's proportions ranging from the semi-square LC-1 $=(30 * 25 \mathrm{~m}$ - aspect ratio $=1: 0.8)$ to the most linear rectangle LC-5 $=(20 * 37.5 \mathrm{~m}$ - aspect ratio $=1: 1.8)$ and 5 courtyard proportions ranging from the semi-square courtyard C-30 $=(30 * 25 \mathrm{~m}$ - aspect ratio $=1: 0.8)$ to the most linear rectangle courtyard $\mathrm{C}-10=$ $(10 * 37.5 \mathrm{~m}$ - aspect ratio=1:3.8). The modeled cases maintained the building standards' spatial requirements of all the indoor spaces including the central breakout space (see Figure 4). 


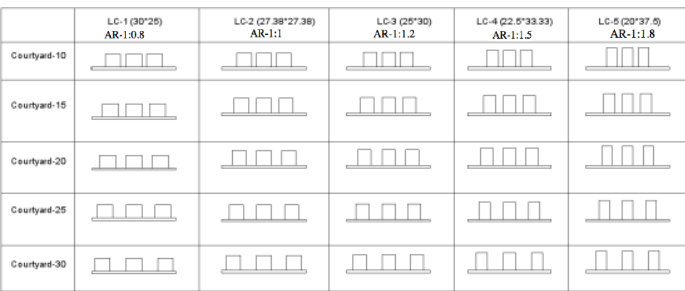

Figure 2: Stage one cases (different LC and C)



Figure 3: Different arrangements proposed with each LC proportion.

Stage Two- Effect of Form Height:

Stage two investigates the building height (represented by the number of floors) impact on energy performance. This stage constitutes a total number of 8 different cases (see Figure 5), which are the extreme cases of LC and C from stage one (LC1-C10, LC1-C30, LC5-C10, LC5C30), each with two different number of floors (1 and 2 floors).

The cases of this stage are linked to Relative Compactness (RC) which can be defined as the following: "The Relative Compactness of a shape is derived in that its volume to surface ratio is compared to that of the most compact shape with the same volume" (Mahdavi \& Gurtekin, 2002). RC is considered as an abstractive design form variable that can be used as a useful design tool for unlimited design situations. The reason for using $\mathrm{RC}$ in this stage only is because the cases of the first and second floor differ significantly in terms of their RC, while the cases in the previous stage have the same number of floors and hence their RC is not much different. Table 2 demonstrate all design parameters including the courtyard width (C-Width), the learning community aspect ratio (LC-AR), and the relative compactness of the form (RC) for each case. The table with the help of the results shown in Figures 7-9 help to understand the correlation between these parameters and how it affect energy consumption.



Figure 4: Stage 2 cases (Different number of floors)
Table 2: Cases of Stage Two with their RC calculations.

\begin{tabular}{|l|l|c|c|c|}
\hline $\begin{array}{c}\text { Number } \\
\text { of floors }\end{array}$ & Cases & $\begin{array}{c}\text { C- } \\
\text { Width } \\
(\mathbf{m})\end{array}$ & $\begin{array}{c}\text { LC- } \\
\text { AR }\end{array}$ & RC \\
\hline \multirow{4}{*}{ 1 Floor } & LC1-C10-FLR1 & 10 & $1: 0.8$ & 0.39 \\
\cline { 2 - 5 } & LC1-C30-FLR1 & 30 & $1: 0.8$ & 0.37 \\
\cline { 2 - 5 } & LC5-C10-FLR1 & 10 & $1: 1.8$ & 0.38 \\
\cline { 2 - 5 } & LC5-C30-FLR1 & 30 & $1: 1.8$ & 0.36 \\
\hline 2 Floors & LC1-C10-FLR2 & 10 & $1: 0.8$ & 0.62 \\
\cline { 2 - 5 } & LC1-C30-FLR2 & 30 & $1: 0.8$ & 0.59 \\
\cline { 2 - 5 } & LC5-C10-FLR2 & 10 & $1: 1.8$ & 0.58 \\
\cline { 2 - 5 } & LC5-C30-FLR2 & 30 & $1: 1.8$ & 0.56 \\
\hline
\end{tabular}

Figure 5: Stage two cases ( $E-W$ and $N$-S form axis direction)

\begin{tabular}{|c|c|c|c|c|c|}
\hline & LC-1 $(30 * 25)$ & LC- $5\left(20^{*} 37.5\right)$ & & LC.1 $\left(30^{\circ} 25\right)$ & LC. $5\left(200^{\circ 37.5)}\right.$ \\
\hline Courtyard-10 & 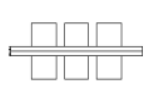 & 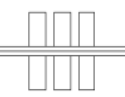 & Courty $x d-10$ & 趴 & $\stackrel{\square}{\square} \square$ \\
\hline Courtyard-30 &  & & Couttyard-30 &  & $\begin{array}{l}\square \\
\square \\
\square \\
\square\end{array}$ \\
\hline
\end{tabular}

Stage Three - Effect of Form Orientation: aims to verify if change of building orientation will make considerable change in energy performance. This stage consists of 8 different cases (see Figure 6); which are a combination of the two extreme cases of LC (LC-1 and LC-5) with the two extreme cases of the $\mathrm{C}(\mathrm{C}-10$ and $\mathrm{C}-30)$ under two different orientations (E-W and $\mathrm{N}-\mathrm{S}$ form axis directions).

The main performance variable in this study is Energy Performance, it is expressed in $\mathrm{MJ} / \mathrm{m}^{2}$ per year unit, the EUI or the total energy consumed by the building in one year (measured in MJ) by the total gross floor area of the building. In addition to Energy performance, this study investigates the environmental impact of $\mathrm{CO}_{2}$ emissions levels in metric tons.

\section{Results}

\section{Energy Consumption}

\subsection{Stage One - Effect of LC and C Proportion}

The energy consumption results of stage one are presented in Figure 7. The changes in LC and C proportions have a remarkable impact on energy consumption. Generally, the LC-5 cases (The most linear cases) have more potential to save energy compared to the other cases (The most squared cases). The reduction varies from 5.5-12.4 $\mathrm{MJ} / \mathrm{M}^{2}$. Y depending on the courtyard width. Regarding the change in the courtyard proportions, the $\mathrm{C}-10$ cases (The most linear cases) have 
more potential to save energy compared to C-30 cases (The most squared cases). The reduction varies from 7.217.9 $\mathrm{MJ} / \mathrm{M}^{2}$. Y depending on the LC proportion.

The difference in energy performance between the best and worst LC cases (LC-5 and LC1, respectively) under different courtyard combinations is shown in Table 2 . Table 3 represents the difference in energy performance between the best and worst $\mathrm{C}$ cases (C-10 and C-30 respectively) under different $\mathrm{LC}$ combinations.

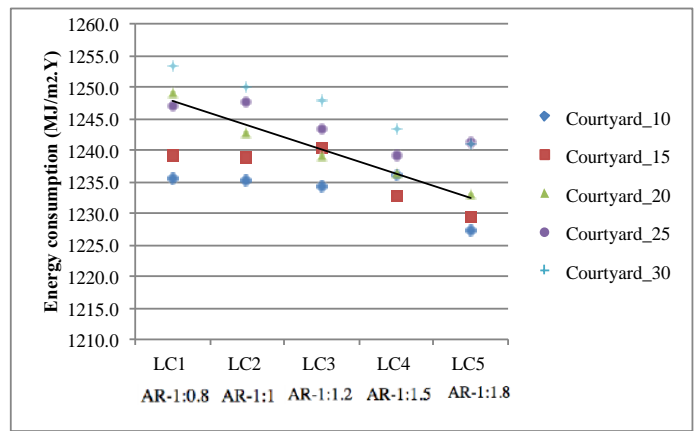

Figure 6: Energy consumption results, stage one

Table 3: Difference in performance between LC-5 and LC-1 tested under different courtyards, stage 1.

\begin{tabular}{|l|l|}
\hline Cases & $\mathbf{L C}-1-\mathbf{L C}-5\left(\mathbf{M J} / \mathbf{m}^{2} \cdot \mathbf{y}\right)$ \\
\hline C-10 & 8.4 \\
\hline C-15 & 9.8 \\
\hline C-20 & 16.1 \\
\hline C-25 & 5.5 \\
\hline C-30 & 12.4 \\
\hline
\end{tabular}

Table 4: Difference in performance between C-30 and $C-10$ tested under different LCs, stage 1 .

\begin{tabular}{|l|l|}
\hline Cases & $(\mathbf{C - 3 0}-\mathbf{C - 1 0})\left(\mathbf{M J} / \mathbf{m}^{2} \cdot \mathbf{y}\right)$ \\
\hline LC-1 & 17.9 \\
\hline LC-2 & 15 \\
\hline LC-3 & 13.7 \\
\hline LC-4 & 7.2 \\
\hline LC-5 & 13.9 \\
\hline
\end{tabular}

\subsection{Stage Two - Effect of Form Height}

Results indicate that the building height (presented by the number of floors) has the most significant impact on energy consumption compared to the other variables (LC and $\mathrm{C}$ ). The increase in the number of floors resulted in a decrease in energy consumption. A reduction of $41-46 \%$ was attributed to the change of the building height from 1 to 2 floors (see Table 4). This pattern was consistent across all the tested cases (see Figure 8).

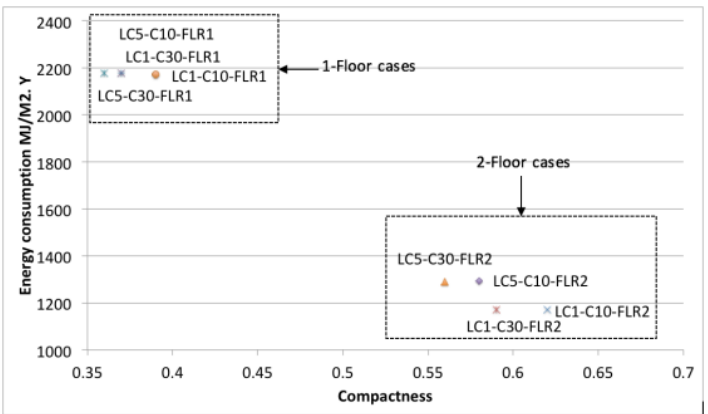

Figure 7: Energy consumption and compactness results expressed in MJ/m2.y, stage 2.

Table 5: Difference of energy conusmption between LC cases, stage 2.

\begin{tabular}{|c|c|c|c|c|}
\hline Cases & $\begin{array}{l}\text { EUI } \\
1 F L R \\
\left(\mathbf{M J} / \mathbf{m}^{2} \cdot \mathbf{y}\right)\end{array}$ & $\begin{array}{l}\text { EUI } \\
2 F L R \\
\left(\mathbf{M J} / \mathbf{m}^{2} \cdot \mathbf{y}\right)\end{array}$ & $\begin{array}{l}\text { 1FLR- } \\
\text { 2FLR } \\
\left(\mathbf{M J} / \mathbf{m}^{2} \cdot \mathbf{y}\right)\end{array}$ & $\begin{array}{l}\% \text { of } \\
\text { Reduction }\end{array}$ \\
\hline $\mathrm{LC} 1-\mathrm{C} 10$ & 2173.4 & 1172.15 & 1001.25 & $46 \%$ \\
\hline LC1-C30 & 2177.5 & 1170.65 & 1006.85 & $46 \%$ \\
\hline LC5-C10 & 2176.8 & 1294.15 & 882.65 & $41 \%$ \\
\hline LC5-C30 & 2178.7 & 1291.35 & 887.35 & $41 \%$ \\
\hline
\end{tabular}

\subsection{Stage Three - Effect of Form Orientation}

The energy consumption results of stage three are presented in Figure 9. Generally, the N-S form axis direction proved to perform better than the E-W form axis direction. The performance pattern observed in phase one can be observed here; the change in LC and courtyard under different form axis direction has a remarkable impact on energy consumption. The LC-5 cases (The most linear cases) have higher potential to save energy compared to the other cases (The most squared cases). The difference between the LC cases with different combinations of $\mathrm{C}$ is presented in Table 5 while Table 6 presents the difference between the $\mathrm{C}$ cases with different combinations of LC.



Figure 8: Energy consumption results, stage two, E-W and $N$-S form axis direction. 
Table 6: Difference in performance between $L C-5$ and $L C-1$ tested under different courtyard and form axis combinations (stage 3).

\begin{tabular}{|l|l|}
\hline Cases & $\mathbf{L C}-\mathbf{1}-\mathbf{L C}-\mathbf{5}\left(\mathbf{M J} / \mathbf{m}^{\mathbf{2}} \mathbf{. y}\right)$ \\
\hline C-10/E-W & 9.27 \\
\hline C-30/E-W & 10 \\
\hline C-10/N-S & 14.75 \\
\hline C-30/N-S & 11.15 \\
\hline
\end{tabular}

Table 7: Difference in performance between $C$-10 and $C$-30 tested under different $L C$ and form axis combinations (stage 3).

\begin{tabular}{|l|l|}
\hline Cases & $\mathbf{C - 3 0}-\mathbf{C - 1 0}\left(\mathbf{M J} / \mathbf{m}^{2} . \mathbf{y}\right)$ \\
\hline LC-1/E-W & 19.1 \\
\hline LC-5/E-W & 18.35 \\
\hline LC-1/N-S & 11.25 \\
\hline LC-5/N-S & 14.25 \\
\hline
\end{tabular}

\section{2. $\mathrm{CO}_{2}$ Emissions:}

$\mathrm{CO}_{2}$ emissions indicate the same pattern found in energy consumption, the results of any case reflect direct dependency on energy consumption results, the increase in energy consumption leads to an increase in $\mathrm{CO}_{2}$ emissions. Therefore, the smallest reduction in energy consumption leads to an equal level of improvement on the environment. $\mathrm{CO}_{2}$ results from stage one, two, and three can be seen in Figures 10, 11, and 12 respectively. A reduction that equals to 30.42 metric tons per year was found between the worst (LC1-C30) and best case (LC5$\mathrm{C} 10)$ in stage one. In stage two the average reduction between the cases with one floor and the cases with 2 floors equals to 2258.6 metric tons per year. While in stage three, the reduction between the worst (LC1-C30) and best case (LC5-C10) equals to 32.8, and 29.6 metric tons per year with E-W and N-S form axis directions respectively.

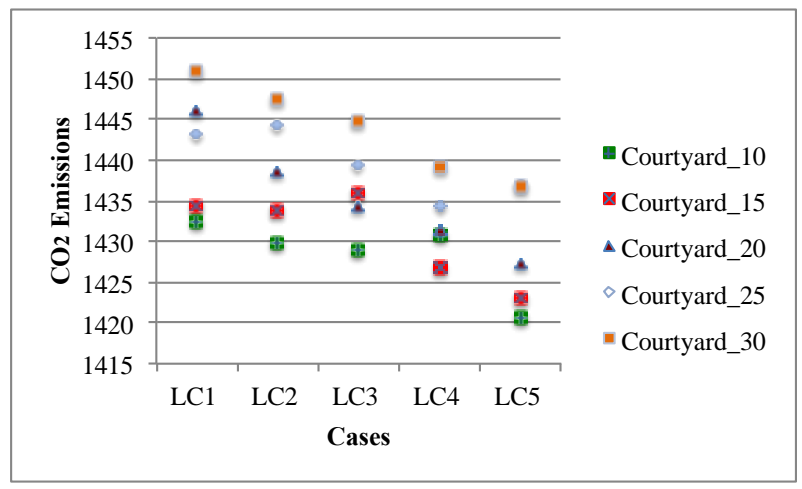

Figure 9: Results of $\mathrm{CO}_{2}$ emission expressed in Metric tons per year, stage 1 .



Figure 10: Results of $\mathrm{CO}_{2}$ emission expressed in Metric tons per year, stage 2.

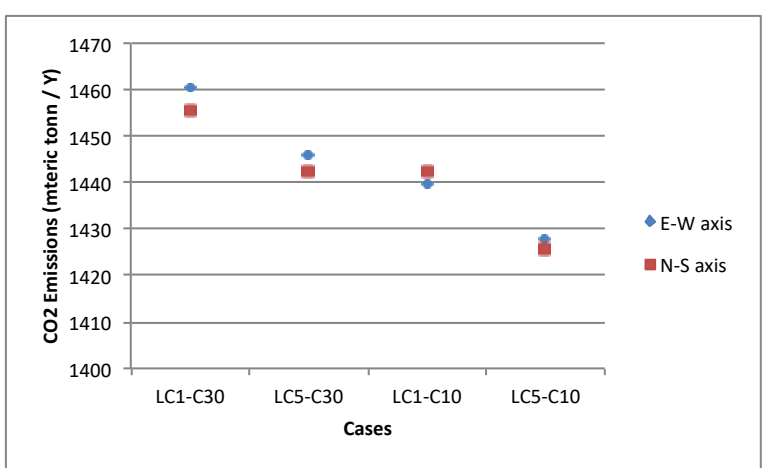

Figure 11: Results of $\mathrm{CO}_{2}$ emission expressed in Metric tons per year, stage 3 .

\section{Discussion}

The difference in performance between the linear and the squared forms of the same height can be attributed to the shading effect. The position of the masses in the cases with the most linear LC and C forms (LC-5/C10) provides more shaded surfaces compared to the squared LC and $\mathrm{C}$ forms. Yet, this pattern was not consistent in the cases of different building height. The third variable, which is the number of floors proved to have a major impact on energy consumption, this result confirm the findings of previous studies. The impact caused by changing the design to a vertical form (i.e. 2 floors instead of 1 floor while keeping the same floor area) resulted in considerable energy savings. This is most attributable to the minimized building surfcaes that are exposed to summer solar radiation. This effect is maximized in a climate like Abu Dhabi, which is located near the tropic of cancer (Latitude 23.5) where the solar radiations are perpendicular on the roof surface during the hottest months of the year. In the cases of 2-floors, the exposed roof area is almost half of that of the 1-floor.

\section{Conclusion}

The study investigated the impact of the building form on energy performance of ADEK schools. A total number of 41 cases were evaluated in terms of energy consumption and GHG emissions using energy simulation. The following conclusions can be drawn: 
- Generally, the linear LC and C form proportions (Highest aspect ratio) perform better than the squared ones (lower aspect ratio). This was evident in the majority of the cases sharing the same volume, floor area, height, glazing size and form axis direction. By comparing between the impact of $\mathrm{C}$ and LC on energy consumption it was found that the change in $\mathrm{C}$ proportions tend to have higher potential to save energy (average reduction of $13.5 \mathrm{MJ} / \mathrm{m}^{2}$. Y than the change in LC (average reduction of $10.4 \mathrm{MJ} / \mathrm{m}^{2}$. Y). The same pattern was observed with $\mathrm{N}-\mathrm{S}$ and E-W form axis directions.

- Building height has higher potential to save energy than the other variables. Changing the building height from 1 to 2 floors resulted in reducing the energy consumption up to $46 \%$.

- The N-S form axis direction proved to perform better than the E-W form axis direction in most cases with an average reduction of $2.2 \mathrm{MJ} / \mathrm{m}^{2}$.Y.

- $\mathrm{CO}_{2}$ emission results demonstrated a direct dependency on energy consumption.

\section{References}

ADEK, 2013, Educational Facilities Design Manual, Abu Dhabi. UAE.

Al-Anzi, A., Seo, D., and Krarti, M. (2009). Impact of building shape on thermal performance of office buildings in Kuwait. Energy Conversion and Management, 50(3), 822-828. https://doi.org/http://dx.doi.org/10.1016/j.enconman. 2008.09.033

Al-Mandoos, A. A. (2005, February). Synoptic and atmospheric stability classification for the United Arab Emirates (Doctoral dissertation, The Witwatersrand, johannesburg, 2005)

Al-Sallal, K. A. (2016). Low Energy Low Carbon Architecture: Recent Advances \& Future Directions. CRC Taylor and Francis Group. Retrieved from https://www.crcpress.com/Low-Energy-Low-

Carbon-Architecture-Recent- Advances--FutureDirections/AlSallal/9781138027480.

Catalina, T., Virgone, J., \& Iordache, V. (2011). Study on the impact of the building form on the energy consumption. In Proceedings of building simulation. Retrieved from http://www.ibpsa.org/proceedings/BS2011/P_1563.p df

Clarke, K. (2016, February 04). 80\% energy consumed by buildings. Retrieved December 26, 2017, from https://www.khaleejtimes.com/nation/abu-dhabi/80energy-consumed-by-buildings

Depecker, P., Menezo, C., Virgone, J., \& Lepers, S. (2001). Design of buildings shape and energetic consumption. Building and Environment, 36(5), 627-
635. https://doi.org/http://dx.doi.org/10.1016/S03601323(00)00044-5

EPA. (2009). Buildings and the Environment: A Statistical Summary. U.S. Environmental Protection Agency Green Building Workgroup.

Frumkin, H., Geller, I., Rubin, L., \& Nodvin, J. (2006). Safe and Healthy School Environments. Retrieved from

http://www.oxfordscholarship.com/view/10.1093/acp rof:oso/9780195179477.001.0001/acprof9780195179477

Koranteng, C., and Abaitey, E. G. (2010). The Effects of Form and Orientation on Energy Performance of Residential Buildings in Ghana. Journal of Science and Technology (Ghana), 30(1). https://doi.org/10.4314/just.v30i1.53940

Lechner N. Heating, Cooling, Lighting: Design Methods for Architects. John Wiley \& Sons, INC.; 1991.

Leslie, R. P. (2010). Patterns to Daylight Schools for People and Sustainability. Lighting Research Center, Rensselaer Polytechnic Institute. Retrieved from https://books.google.ae/books?id=klpXMwEACAAJ

Naboni E, Malcangi A, Zhang Y, Barzon F, Defining The Energy Saving Potential of Architectural Design. 7th International Conference on Sustainability in Energy and Buildings; 2015.

Ourghi, R., Al-Anzi, A., and Krarti, M. (2007). A simplified analysis method to predict the impact of shape on annual energy use for office buildings. Energy Conversion and Management, 48(1), 300305.https://doi.org/http://dx.doi.org/10.1016/j.encon man.2006.04.011

Pessenlehner, \& Mahdavi. (2003). Building morphology, transparency, and energyperformance. ResearchGate. Retrieved from https://www.researchgate.net/publication/237581710 _Building_morphology_transparency_and_energy_p erformance 